\title{
Nada mais humano do que o direito a ser corpo
}

https://doi.org/10.11606/issn.1981-4690.v35inespp7-14

\author{
J air Wesley Ferreira Bueno* \\ Edison de J esus Manoel ${ }^{*}$
}

*Escola de Educação

Física e Esporte,

Universidade de São

Paulo, São Paulo, SP,

Brasil.

\section{Resumo}

Este ensaio tem como objetivo propor demandas para estudos que podem compor o contexto reflexivo a ser incentivado pelo Núcleo de Direitos Humanos (NDH) da Escola de Educação Física e Esporte (EEFE) da Universidade de São Paulo (USP). Sobre a ótica do acesso e da promoção da educação em direitos humanos como temática, adota os direitos que NDH selecionou para contemplar ações educativas na EEFE-USP: acesso, igualdade, liberdade, proteção e permanência. Assume que os direitos humanos, ao mesmo tempo que fundamentam, mantêm uma relação de sinergia com o desenvolvimento humano. E mais, desenvolvimento e direitos, apenas serão alcançados a partir do entendimento do corpo que somos. Mais especificamente, sobre o desenvolvimento e os direitos, sugere uma reflexão com base nos pilares apresentados pelo Programa das Nações Unidas para o Desenvolvimento (PNUD). Para o corpo que somos, menciona a noção de corporeidade. Ainda, propõe uma reflexão a partir da fenomenologia e das ciências cognitivas. Apoiado na compreensão que a escola é um espaço importante na formação do ser humano, cuja relação desenvolvimento humano, corpo e direitos humanos pode ser valorizada e explorada, apresenta uma reflexão sobre o mover-se corporal dentro de um modelo de Escola Ativa proposto pelo PNUD. Por fim, conclui que as reflexões propostas são necessárias e atuais, pois enfatizam a experiência que é possível ser vivida pela corporeidade. Isso é fundamental para o desenvolvimento e a garantia dos direitos.

Palavras-Chave: NDH-EEFE-USP; Direitos humanos; Desenvolvimento humano; Escola; Corporeidade.

\section{Introdução}

A Declaração Universal dos Direitos Humanos ${ }^{1}$ (DUDH) proclamada em 10 de dezembro de 1948, considera em seu preâmbulo "que o reconhecimento da dignidade inerente a todos os membros da familia humana e de seus direitos iguais e inalienáveis é o fundamento da liberdade, da justiça e da paz no mundo [...]". Vamos mal numa sociedade quando tais fundamentos são desrespeitados. Ferir o que deveria ser inerente ao ser humano, a sua dignidade e os seus direitos, pode resultar em atos bárbaros. Este ensaio assume com base no artigo 26, parágrafo primeiro da $\mathrm{DUDH}^{1}$, o reconhecimento da educação como um direito universal, sendo o ensino superior pautado no mérito. Ainda, o artigo 26, segundo parágrafo, revela: A instruçáo será orientada no sentido do pleno desenvolvimento da personalidade humana e do fortalecimento do respeito pelos direitos do ser humano e pelas liberdades fundamentais. A instrução promoverá a compreensão, a tolerância e a amizade entre todas as naçôes e grupos raciais ou religiosos e coadjuvará as atividades das Naçôes Unidas em prol da manutenção da paz. Assim, açóes propostas pelo Núcleo de Direitos Humanos (NDH) da Escola de Educação Física e Esporte (EEFE) da Universidade de São Paulo (USP), possibilitam expressar o entendimento da educaçáo em direitos humanos no ensino superior. Além disso, oferecem a oportunidade de discutir o que sabemos, o que estamos fazendo e para onde caminhamos enquanto universidade em relação a essa temática. Este ensaio considera que alguns pontos perpassam a temática dos direitos humanos, e que a dignidade e a liberdade adotadas e proclamadas pela DUDH ${ }^{1}$ estão integradas ao desenvolvimento humano. É válido destacar que, embora desenvolvimento tenha um amplo sentido, aqui, refere-se fundamentalmente as mudanças que ocorrem ao longo da vida das pessoas, o que lhes permite ocupar, agir e transformar o meio em que vivem. A definiçấo de desenvolvimento humano apresentada pelo economista AmarTya SEN ${ }^{2}$ 
é inserida nesta concepção, e fornece um modelo de políticas públicas que tenham como foco o agenciamento da qualidade de vida das pessoas. Para ele, o desenvolvimento "é um processo de expansão das liberdades reais que as pessoas desfrutam" (p.17) e, portanto, "a condição de agente livre e sustentável emerge como motor fundamental do desenvolvimento" 2 (p.19).

Aprofundar-se na dignidade, na liberdade, no desenvolvimento humano e nos direitos humanos, perpassa pelo corpo, esse espaço de ser e de tornarse. Não há dignidade, liberdade, desenvolvimento humano e direitos humanos, sem um entendimento do corpo que somos, sem ter em conta que nossa existência é corporificada. Esse sentido é essencial e se aproxima do próprio viver, o que desperta a necessidade de entender o ser humano em sua totalidade. Portanto, este ensaio tem como objetivo

\section{Direitos humanos}

\section{Sobre desenvolvimento humano e direitos humanos}

A DUDH ${ }^{1}$ apresenta o ideal comum a ser alcançado por todas as naçóes, promovendo o respeito aos direitos e liberdades por meio do ensino e da educação. De particular interesse para este ensaio destaca-se o artigo I: "Todos os seres humanos nascem livres e iguais em dignidade e direitos. São dotados de razão e consciência e devem agir em relação uns aos outros com espirito de fraternidade".

A compreensão dos direitos selecionados pelo NDH-EEFE-USP (Quadro 1), revela para este ensaio, estreita relação com o desenvolvimento humano. Ao mesmo tempo que fundamentam, esses direitos mantém uma relação de sinergia com o desenvolvimento. A perspectiva adotada por esse ensaio reconhece que o humano é uma construção histórica, o que permite sugerir que o desenvolvimento humano não é definitivo. Ou seja, é um processo, portanto, dinâmico. O United Nations Development Programme ${ }^{3}$ (UNDP) apresentou:

O desenvolvimento humano tem a ver com as pessoas - expandindo suas liberdades, ampliando suas escolhas, aprimorando suas capacidades e melhorando suas oportunidades. É um processo e também um resultado. $\mathrm{O}$ crescimento econômico e a renda são meios para o desenvolvimento humano, mas não um fim em si mesmos - porque é a riqueza da vida das pessoas, não a riqueza das economias, propor demandas para estudos que podem compor o contexto reflexivo a ser incentivado pelo $\mathrm{NDH}$ da EEFE-USP. Sobre a ótica do acesso e da promoção da educação em direitos humanos como temática, adota os direitos que NDH selecionou para contemplar açóes educativas na EEFE-USP: acesso, igualdade, liberdade, proteção e permanência. Contudo, não tem a pretensão de aprofundar-se em cada um desses direitos, mas entende que essencialmente eles têm um sentido existencial, a saber, refletir sobre o acesso à educação em direitos humanos a partir dos direitos selecionados, é pensar sobre a relação de tais direitos com o desenvolvimento humano e o corpo. Juntos, constituem elementos fundamentais no processo de construção da história de cada cidadão (ã). Por fim, considera que as reflexōes propostas podem circular as atividades-fim (ensino, pesquisa e extensão) e as atividades-meio (gestão) na EEFE-USP. que em última análise tem valor para as pessoas. Com uma noção tâo simples, mas poderosa, o primeiro Relatório de Desenvolvimento Humano, publicado em 1990, colocou as pessoas no centro do discurso do desenvolvimento, mudando a lente para avaliar as políticas de desenvolvimento e seus resultados. (p. 25).

Logo, a avaliaçấo de desenvolvimento considera "as coisas que as pessoas podem ser e fazer em suas vidas, tanto agora como no futuro" (p.20). O Programa das Nações Unidas para o Desenvolvimento 5 (PNUD), tem destacado em seus relatórios o entendimento proposto pelo economista Amartya Sen "de que o desenvolvimento humano consiste em ampliar as opçóes reais das pessoas, para que possam escolher um modo de vida que valorizam"s (p.41). Sobre o significado de ampliação das opçóes das pessoas o $\mathrm{UNDP}^{6}$ destacou:

O desenvolvimento humano é a ampliação das liberdades das pessoas para que tenham vidas longas, saudáveis e criativas, para que antecipem outras metas que tenham razóes para valorizar e para que se envolvam ativamente na definição equitativa e sustentável do desenvolvimento num planeta partilhado. As pessoas são, ao mesmo tempo, os beneficiários e os impulsores do desenvolvimento humano, tanto individualmente como em grupos. (p. 24).

A concepção de desenvolvimento humano ganha perspectiva importante com a abordagem 
de Capacidades Humanas de Nussbaum ${ }^{7}$. Se a definição de desenvolvimento de Amartya Sen destaca a potência humana de talhar seu próprio percurso desenvolvimentista, Martha Nussbaum nos aponta para a necessidade de considerar as condiçóes estruturantes que se dispóem nesse percurso. Nussbaum mostra grande preocupação com os impactos negativos que injustiça social e desigualdade estrutural impóem na tessitura do desenvolvimento humano: a necessária articulação do desenvolvimento individual com o desenvolvimento social.

O PNUD 5 em consideração com as duas perspectivas indicou os seguintes elementos como pilares do desenvolvimento humano:
Bem estar: ampliar as liberdades reais das quais dispóem as pessoas, isto é, o espectro de oportunidades em suas vidas; empoderamento e agência: favorecer a participação das pessoas e grupos motivados por um interesse comum, para conseguir mudanças e resultados desejáveis; justiça: respeitar e promover a equidade entre as pessoas e preservar os resultados no tempo com base no respeito aos direitos humanos e nos objetivos estabelecidos pela sociedade. (p. 44).

Como uma das contribuiçóes da educaçáo em direitos humanos é a transformação social, parece relevante que os pilares apontados pelo PNUD 5 , bem estar, empoderamento e justiça, sejam discutidos em açôes educativas sobre direitos humanos na EEFE-USP.

QUADRO 1- Direitos selecionados da DUDH.

\begin{tabular}{|c|c|}
\hline Direitos & Ideais \\
\hline Acesso & $\begin{array}{l}\text { Compreende direitos, como por exemplo, o direito à vida, de ser reconhecido como pessoa } \\
\text { perante a lei, a uma nacionalidade, à propriedade, ao trabalho, de fazer parte do governo do } \\
\text { seu país, à instruçáo. Ou seja, expressa a possibilidade do ser humano acessar e agir em diversas } \\
\text { instâncias sociais presentes desde sua concepçáo e passando pelas fases ao longo da vida, de forma } \\
\text { a interagir em situaçóes variadas de relacionamento interpessoal, trabalho e lazer. }\end{array}$ \\
\hline Igualdade & $\begin{array}{l}\text { Compreende citaçóes diretas, como por exemplo, o direito a nenhuma distinção fundada } \\
\text { na condição política, jurídica ou internacional do país ou território a que pertença a uma } \\
\text { justa e pública audiência por parte de um tribunal independente e imparcial; a contrair } \\
\text { matrimônio e fundar família, homens e mulheres de maior idade, sem qualquer restrição de } \\
\text { raça, nacionalidade ou religião; de acesso ao serviço público do seu país; a condiçôes justas } \\
\text { e favoráveis de trabalho e à proteção contra o desemprego; a igual remuneração por igual } \\
\text { trabalho; a uma remuneração justa e satisfatória. }\end{array}$ \\
\hline Liberdade & $\begin{array}{l}\text { Corresponde a direitos para viver, pensar, exprimir e agir, como por exemplo, o direito contra } \\
\text { a manutenção da pessoa como escravo ou servidão; a locomoção e residência dentro de um } \\
\text { Estado; a procurar asilo em outro país; de pensamento, consciência e religião; de opinião e } \\
\text { expressão; de reunião e associação pacífica; livre escolha de emprego. }\end{array}$ \\
\hline Proteção & $\begin{array}{l}\text { Compreende direitos, como por exemplo, o direito à segurança pessoal; à segurança social; } \\
\text { à proteçáo dos interesses morais e materiais decorrentes de qualquer produçáo científica } \\
\text { literária ou artística da qual seja autor; a uma ordem social e internacional que assegurem } \\
\text { o cumprimento dos direitos humanos; a não ser sujeito à interferência em sua vida privada, } \\
\text { em sua família, em seu lar ou em sua correspondência, nem a ataque à sua honra e reputaçáo. } \\
\text { Agrega de forma direta as citaçóes diretas expressas na DUDH, com referência à necessidade } \\
\text { de proteção para ser, pertencer, agir e permanecer vivo. }\end{array}$ \\
\hline Permanência & $\begin{array}{l}\text { Expressa direitos humanos que refletem a necessidade de assegurar um suporte para poder } \\
\text { manter a sua vida em plenitude, como por exemplo, o direito a um padrão de vida capaz de } \\
\text { assegurar-lhe, e a sua família, saúde e bem-estar, inclusive alimentação, vestuário, habitação, } \\
\text { cuidados médicos e os serviços sociais indispensáveis. }\end{array}$ \\
\hline
\end{tabular}

Fonte: NDH-EEFEUSP. 


\section{O corpo que somos}

O queéfeito a seguir, sugere que o desenvolvimento humano e os direitos, podem apenas ser atingidos a partir do reconhecimento do corpo que somos. Esse olhar sobre o corpo, por sua vez, corrobora a noção central da corporeidade na existência humana ${ }^{8}$. A corporeidade permite a interaçáo com o meio e fundamenta o desenvolvimento das capacidades humanas. As capacidades referem-se às condiçóes e às oportunidades para uma pessoa ser o que desejar ${ }^{7}$, e representam as liberdades das quais uma pessoa usufrui para levar o tipo de vida que valoriza ${ }^{4}$. Dessa forma, as pessoas são livres para escolher o que querem ser ou fazer. Esse pensamento orienta a narrativa de que essas escolhas estão fundamentadas nos direitos humanos que garantirão tal liberdade.

Para este ensaio, o desenvolvimento humano atenta-se à construção das capacidades humanas. As capacidades abarcam escolhas garantidas pelos direitos humanos. Assim, concorda que a corporeidade descreve uma dimensão humana ${ }^{8}$, e por meio do corpo que somos, podemos interagir com o meio e fazer valer os nossos direitos e escolhas. Nessa concepção, o acesso à educação em direitos humanos precisa discutir a corporeidade. Como sugestão, a reflexão sobre corporeidade a ser incentivada pelo $\mathrm{NDH}$ pode partir do significado do termo corpo em uso pela perspectiva fenomenológica. Vale destacar que para Merleau-Ponty ${ }^{9}$, a percepção emerge de um corpo em movimento:

Não é o sujeito epistemológico que efetua a síntese, é o corpo, quando sai de sua dispersão, se ordena, se dirige por todos os meios para um termo único de seu movimento, e quando, pelo fenômeno da sinergia, uma intenção única se concebe nele. (p. 312).

Outra importante implicação para a reflexão sobre a corporeidade tem se originado das ciências $\operatorname{cognitivas~}^{10,11}$. Mais especificamente, a enação $o^{a}$ considera que o conhecimento é incorporado. Somos um corpo com infinitas possibilidades sensóriomotoras interagindo com o mundo. $\mathrm{O}$ conhecer surge da corporeidade e depende da experiência que acontece na ação corporal ${ }^{11}$. Isto posto, ao pensar com base na fenomenologia ${ }^{9}$ e nas ciências cognitivas ${ }^{10,11}$, compreendemos que vida é movimento. O ser humano precisa movimentar-se, e movimentandose ele ocupa e torna o ambiente em espaços de ação. Os processos sensório-motores, percepção e ação, são inseparáveis do conhecimento, da cogniçãa ${ }^{11}$.
Discutir o acesso aos direitos humanos baseado na corporeidade é reconhecer que a cognição emerge da corporeidade. Diante disso, somos corpos em movimento ocupando espaços. Alicerçados nessa proposiçáo, considera-se a unidade mente-corpo como inseparável, servindo-se da relação e das experiências que cada indivíduo experimenta no mundo. Pensar os direitos humanos a partir da reflexão sobre corporeidade, é valorizar a vivência do corpo. De mais a mais, valorizar o corpo que é a expressão individual de cada cidadão (ã). Além disso, é reconhecer no corpo do outro a possibilidade de espaços coletivos de ação. Nessa direção, o reconhecimento das liberdades consolidadas nos direitos humanos nasce de um olhar sensível. A partir da percepção que o ser humano pode atribuir sentidos a sua existência, assume-se a sensibilidade humana, capaz de reconhecer o que de fato pertence a cada um. Desse modo, com base no corpo que somos carregamos a nossa historicidade e agimos no mundo, fazemos valer os nossos direitos e liberdades. De igual valor, reconhecemos e respeitamos os direitos e liberdades do outro.

\section{O espaço escolar}

Até aqui, este ensaio propôs a reflexão de que os direitos humanos selecionados para embasá-lo (Quadro 1), ao mesmo tempo que fundamentam, mantém uma relação de sinergia com o desenvolvimento humano. Além de que, sugeriu que para alcançar ambos, desenvolvimento e direitos, precisamos discutir o corpo que somos. Apoiado na compreensão que a escola é um espaço importante na formaçáo do ser humano, cuja relaçáo desenvolvimento humano, corpo e direitos humanos poderia ser valorizada e explorada, apresenta uma reflexão sobre o mover-se corporal dentro de um modelo de Escola Ativa proposto pelo PNUD ${ }^{5,12}$ Brasil. Como ponto central, essa proposta valoriza o desenvolvimento humano através do mover-se corporal no espaço da escola.

Reconhecendo a possibilidade de que muitos alunos e alunas da EEFE-USP serão professores e professoras escolares, essa reflexão é válida para que possam na realizaçáo de suas atribuiçóes serem agentes protagonistas. No caso específico da Educaçáo Física (EF), é razoável supor o seu relevante papel no contexto da Escola Ativa, uma vez que a EF revela-se no entendimento dado a um corpo que sofre influências culturais ${ }^{13}$. Também a EF pode contribuir para que crianças e jovens reflitam sobre 
seu corpo e suas práticas ${ }^{14}$. Porém, a noção de ser ativa é um projeto de toda a escola, e dessa maneira, deve ser discutida a partir do envolvimento de todos os atores presentes no cotidiano e na cultura escolar. A cultura escolar pode ser entendida como gestores (as), diretores (as), coordenadores (as), professores (as) e funcionários (as) se organizam, compreendem e recebem o mover-se corporal dos alunos e alunas no espaço da escola. Isso deve se manifestar na arquitetura, nas rotinas, no currículo, no diálogo e nas aulas. Ainda, o que é tratado a seguir não se limita aos alunos de licenciatura, pois coloca o corpo, o mover-se corporal como elemento central no processo de construção do desenvolvimento humano.

\section{Escola ativa: o mover-se corporal}

Sem entrar na análise das várias influências teóricas que adentraram a Educação e consequentemente a escola até hoje, é correto dizer que diferentes visões são postas e definem correntes pedagógicas dicotômicas. Nesse cenário, aparece o conceito de Escola Ativa, cuja importância está pautada em evitar os efeitos deletérios do sedentarismo e aumentar as oportunidades de atividade física durante o período escolar, o que melhorará o desempenho acadêmico das crianças. Entretanto, um olhar emancipador encontrará antes de um processo regular, construção, criação, novidade e recriação ${ }^{5,12}$. A partir desse novo olhar, pode-se encontrar a perspectiva de que somos sujeitos do nosso próprio desenvolvimento. Nesse contexto, a escola é um espaço de desenvolvimento, lugar em que as crianças e os jovens são entendidos como sujeitos pedagógicos. Então, surge um conceito alternativo de Escola Ativa proposto pelo PNUD ${ }^{12}$ no Brasil. De acordo com o PNUD ${ }^{12}$ uma escola é ativa quando:

[...] se organiza como espaço pessoal, social e institucional voltado ao Desenvolvimento Humano, entendido como processo de ampliação das capacidades e consequentemente das possibilidades de escolha das pessoas. Há três pontos chaves para essa conceituação. Primeiro, a escola é o sítio da construção do processo civilizatório de uma sociedade, e assim, crianças, jovens e professores interagem e se fazem como sujeitos do conhecimento [...]. Segundo, a escola pode ser o espaço para capitalizar o mover-se corporalmente da criança e do jovem e com ele potencializar as açóes de conhecer sobre o mundo e de transformar o mundo [...]. Terceiro, a escola é encontro. O encontro com o outro, o encontro consigo, o encontro do corpo e da mente, o encontro como exercício do autoconhecimento, o encontro como convergência do natural e do cultural, do biológico e do social. (p.3-5).

Particularmente, o que desperta interesse de fato, considera o que é ser uma Escola Ativa com base no conceito apresentado pelo $\mathrm{PNUD}^{12}$. Também o que expressa o adjetivo ativa. Uma escola que age para que a criança e o jovem sejam agentes de seu desenvolvimento a partir do respeito e a promoção da ampla manifestação de sua corporeidade no ambiente da escola, nas rotinas da escola, e nos vínculos entre escola, família e comunidade $e^{5,12}$. Para mais, na definição apresentada nota-se claramente o desenvolvimento humano como elemento central. Neste ponto, os elementos apresentados por este ensaio que constituem a noção de desenvolvimento humano, podem ser discutidos com base na educação. $\mathrm{O}$ processo de escolarização pode influenciar a capacidade das pessoas para viverem melhor e terem uma vida saudável, ao mesmo tempo em que esses indivíduos estão agindo dentro do contexto que estão inseridos. Esse sentido é essencial, o que desperta a necessidade de entender o ser humano em sua totalidade. Isto é, não apenas as determinaçôes biológicas, mas assumir também a sua cultura ${ }^{15}$, o que ampliará a sua capacidade de atuação no mundo. Açóes corporais influenciam a maneira que os seres humanos fazem uso do seu corpo $^{16}$. O movimento, o mover-se corporal, está intimamente ligado a processos entendidos como intelectuais, como por exemplo, imaginar, perceber, tomar decisóes, programar e avaliar ${ }^{17}$. A partir desse referencial teórico, entende-se que nesse processo, as variáveis biológicas, psicológicas, sociais, culturais $^{15}$ e sensório-motoras ${ }^{17}$ que integram o ser humano, precisam ser vistas como variáveis em um sistema unitário.

Retomando o conceito de Escola Ativa, fica evidente que os pontos chaves que o define estão interligados e assumem o indivíduo em sua totalidade. Isso permite supor que a Escola Ativa reflete um processo em que crianças, jovens e professores interagem e são os sujeitos do conhecimento que está mutuamente relacionado com o mover-se corporal, e ambos influenciam o desenvolvimento humano. Entretanto, um levantamento feito pelo PNUD ${ }^{5}$-Brasil por meio de uma Escala de Escola Ativa (EEA) (insuficiente, elementar, intermediário, avançado e pleno), constatou que uma proporçáo muito pequena 
das escolas brasileiras era avançada (0.52\%) ou plenamente $(0.03 \%)$ ativa, com um número pequeno no nível intermediário (11.29\%) e a maior parte das escolas nos níveis elementar (49.60\%) e insuficiente (38.56\%). Após considerar que, valorizar a vivência do corpo é pensar os direitos humanos baseado na reflexão sobre corporeidade, a perspectiva de desenvolvimento humano apresentada, o reconhecimento da escola como uma oportunidade social e o levantamento feito pelo PNUD 5 -Brasil, este ensaio mostra que é necessário conhecer e saber mais das condições das escolas, as suas potências, as suas possibilidades e os seus obstáculos para se tornarem ativas. Dado o que isso representa para a construção do desenvolvimento humano e a garantia dos direitos. Nesse caminho, indica como proposta de reflexão para a educaçáo em direitos humanos a ser estimulada pelo NDHEEFE-USP, o que impede que uma escola seja ativa em nível avançado ou pleno, ou que progrida para se tornar mais ativa, interpretando a convergência ou náo para o entendimento do mover-se corporal como uma capacidade humana valorosa. Tal reflexáo pode partir do seguinte pressuposto: o lugar do corpo na cultura escolar. Para tanto, é necessária a compreensão do corpo no âmbito da cultura, uma vez que este corpo possui tradição e eficácia simbólica ${ }^{16}$. E mais, deve ser valorizado o processo pelo qual os seres humanos dáo sentido às suas açôes, por meio de manipulações simbólicas próprias da atividade humana ${ }^{18}$.

\section{Escola ativa: mente e corpo na escola}

A escola moderna que se configura no século XIX privilegia o intelecto em detrimento ao corpo. A luz da verdade, nota-se que a dicotomia mente-corpo está presente na concepção de educação de muitas escolas hoje em dia, com a preposição de que o desempenho acadêmico envolve, principalmente, processamento cognitivo. Todavia, como alternativas, surgem metodologias com vertente humanista, sugerindo que a aprendizagem pode ocorrer por diferentes sentidos além do intelectual ${ }^{19}$. De particular interesse, este ensaio aponta a pedagogia que resultou da filosofia proposta por John Dewey. DEWEY $^{20}$ defendeu a aproximação entre a educação e a vida, com destaque a importância das experiências vividas pelas crianças e jovens. Essa pedagogia que é humanista e ativa por valorizar a experimentação do mundo, influenciou o movimento da Escola Nova no Brasil nos anos 1930. Nesse quadro, as abordagens pedagógicas propunham que as experiências vividas na escola estivessem relacionadas com a vida. Assim, os alunos teriam a oportunidade de aprender a conviver em uma sociedade democrática. Para DeweY ${ }^{20}$ a educação é um processo social que representa a própria vida.

O conceito de Escola Ativa foi pensado adotando concepçóes similares, colocando os alunos no centro do processo educacional e como sujeitos da experiência educacional ${ }^{5,12}$. Dessa forma, a aprendizagem acontece em açóes pedagógicas contextualizadas para que os alunos experimentem conhecimentos que serão levados para fora dos muros da escola. Uma Escola Ativa organiza espaços e tempos para que crianças e jovens encontrem liberdade para vivenciar experiências que promovam a construção de sua autonomia e do pensamento crítico e reflexivo sobre sua condição humana e social ${ }^{5}$. Há que lembrar o que foi sugerido por Bondía $^{21}$, a experiência é aquilo que nos toca, e ao nos tocar, nos forma e nos transforma. A noção de liberdade é fundamental para o desenvolvimento ${ }^{2,20}$. $S_{E N}{ }^{2}$ destaca o relevante papel das pessoas como agentes de desenvolvimento. Vale ressaltar que, ${ }_{\text {DEWEY }}^{20}$ fez reflexóes sobre a relação entre liberdade de movimento e liberdade de pensamento:

A limitação que foi imposta sobre as açóes externas pelos arranjos rígidos da típica sala de aula tradicional, com suas fileiras e carteiras fixas e a arregimentaçấo militar de seus alunos que só podiam se movimentar a partir de sinais estabelecidos de permissão, restringiam rigorosamente a liberdade moral e intelectual. (p. 63).

Com isso, a Escola Ativa apoiada na perspectiva citada recebeu um novo significado, e passou também a se referir a uma escola comprometida em garantir o mover-se no cotidiano escolar. Transformar uma escola em ativa, em que a liberdade de mover-se seja aceita, significa construir um sistema educacional de qualidade e plenamente ativo ${ }^{5,12}$. É importante destacar que uma escola pode ser pouco ou muita ativa, mas nunca inativa. Não é possível uma escola e seus alunos serem totalmente inativos.

Embora o corpo e o mover-se sejam reconhecidos no processo educacional, ainda são tratados como elementos secundários na formação das crianças e jovens. De modo geral, o que ocorre nas escolas é um controle sobre o corpo. Aluno(a) mais comportado(a), em outros termos, aquele(a) que menos se movimenta, é mais civilizado(a) e aprende mais. Visto o necessário entendimento do corpo na relação com a construção do processo de 
desenvolvimento humano e a garantia dos direitos humanos, cabe a pergunta: o que acontece quando a escola subestima o corpo de crianças e jovens? A reflexão sobre a compreensão do corpo na educação pode ser sugerida pelo NDH ao tratar a temática educação em direitos humanos. Como sugestão, as reflexóes do filósofo Merleau-Ponty e dos biólogos Maturana e Varela podem fundamentar outras concepçóes, superando a visão de que o corpo é apenas instrumento ou objeto na escolarização.

\title{
Considerações finais
}

Discutir à educação em direitos humanos é fazer pensar sobre a construção do processo de desenvolvimento humano. Tais direitos, ao mesmo tempo que fundamentam, mantém uma relaçáo de sinergia com o desenvolvimento. Ambos, desenvolvimento e direitos, apenas serão alcançados a partir do entendimento do corpo que somos. Assim, este ensaio explicita a relação entre desenvolvimento, corpo e direitos. Atende ao objetivo uma vez que propóe reflexôes entendidas como prementes e necessárias no âmbito da universidade. A reflexão sobre o corpo e o movimento continua atual, pois enfatiza a experiência que é possível ser vivida pela corporeidade, o que coloca as pessoas no centro do conhecimento ${ }^{11}$. Entender o corpo é fundamental para o desenvolvimento humano e a garantia dos direitos, através dele percebemos, experimentamos e interpretamos o mundo. Isso é inerente à dimensão humana.

\section{Nota}

a. Do inglês enaction, termo criado por VARELA et al. ${ }^{11}$ que significa fazer emergir, e ação guiada pela percepção.

\begin{abstract}
Nothing is more human than the right to be body

This essay aims to propose demands for studies that can compose the reflective context to be encouraged by the Human Rights Center (NDH) of the School of Physical Education and Sport (EEFE) of the University of São Paulo (USP). Regarding the perspective of access and the promotion of human rights education as a theme, it adopts the rights that NDH selected to contemplate educational actions at EEFE-USP: access, equality, freedom, protection and permanence. It assumes that human rights, while supporting, maintain a relationship of synergy with human development. Furthermore, development and rights will only be achieved through understanding the body that we are. More specifically, on development and rights it suggests a reflection based on the pillars presented by the United Nations Development Programme (UNDP). For the body that we are, it mentions the notion of corporeality. Still, it proposes a reflection based on phenomenology and cognitive sciences. Supported by the understanding that the school is an important space in the formation of the human being, whose relationship between human development, body and human rights can be valued and explored, it presents a reflection on the bodily movement within an Active School model proposed by UNDP. Finally, it concludes that the proposed reflections are necessary and current, as they emphasize the experience that is possible to be lived by corporeality. This is essential for the development and guarantee of rights.
\end{abstract}

KEYwORDS: NDH-EEFE-USP; Human rights; Human development; School; Corporeality. 


\title{
Referências
}

1. Declaração Universal dos Direitos Humanos. Assembleia Geral das Naçóes Unidas em Paris. 10 dez. 1948.

2. Sen A. Desenvolvimento como liberdade. São Paulo: Companhia das Letras; 2000.

3. UNDP. United Nations Development Programme. Human Development for Everyone. New York: UNDP; 2016.

4. Alkire S, Deneulin S. An introduction to the human development and capability approach. London: Earthscan; 2009.

5. PNUD. Programa das Naçóes Unidas para o Desenvolvimento. Relatório Nacional de Desenvolvimento Humano 2017. Movimento é vida: atividades físicas e esportivas para todas as pessoas. Brasília: PNUD; 2017.

6. UNDP. United Nations Development Programme. The real wealth of nations: pathways to human development. New York: UNDP; 2010.

7. Nussbaum MC. Women and human development: the capabilities approach. Cambridge: Cambridge University; 2000.

8. Whitehead M. Letramento corporal: atividades físicas e esportivas para toda a vida. Porto Alegre: Penso; 2019.

9. Merleau-Ponty M. Fenomenologia da percepção. São Paulo: Martins Fontes; 1994.

10. Maturana H, Varela F. A árvore do conhecimento: as bases biológicas do entendimento humano. Campinas: Psy II; 1995.

11. Varela F, Thompson E, Rosch E. Embodied mind: cognitive science and human experience. London: MIT; 1996.

12. PNUD, INEP. Programa das Naçôes Unidas para o Desenvolvimento. Instituto Nacional de Estudos e Pesquisas Educacionais Anísio Teixeira. Caderno de desenvolvimento humano sobre escolas ativas no Brasil. Brasília: PNUD: INEP; 2016.

13. Bracht V. A constituição das teorias pedagógicas da educaçâo física. Cad O CEDES. 1999;19:69-88.

14. Rasberry CN, Lee SM, Robin L, et al. The association between school-based physical activity, including physical education, and academic performance: a systematic review of the literature. Prev Med. 2011;52:S10-S20.

15. Geertz C. A interpretaçáo das culturas. Rio de Janeiro: Guanabara Koogan; 1989.

16. Mauss M. Sociologia e antropologia. São Paulo: Cosac \& Naify; 2003.

17. Sperry RW. Neurology and the mind-brain problem. Am Scientist. 1952;40:291-312.

18. Daolio J. Consequências do conceito de cultura para a Educação Física escolar. In: Neto, MP, organizador. Desafios da educação física: cultura e corpo em movimento. Dourados: EdUFGD; 2015. p. 57-73.

19. Stehlik T. Thinking, feeling, and willing: how Waldorf schools provide a creative pedagogy that nurtures and develops imagination. In: Leonard T, Willis, P, editors. Pedagogies of the Imagination. Springer Science; 2008. p. 231-243.

20. Dewey J. Democracia e educação: introdução à filosofia da educação. Tradução de Godofredo Rangel e Anísio Teixeira. São Paulo: Nacional; 1979.

21. Bondía JL. Notas sobre a experiência e o saber de experiência. Rev Bras Educ. 2002;19:20-28.

\author{
ENDEREÇO \\ J air Wesley Ferreira Bueno \\ Universidade de São Paulo \\ Escola de Educação Física e Esporte \\ Campus Cidade Universitária \\ Av. Prof. Mello Moraes, 65 \\ 05508-030 São Paulo - SP - Brasil \\ E-mail: jwesleybueno@usp.br \\ E-mail alternativo: wferreirab@gmail.com
}

Recebido: 10/12/2020

Aceito: 18/12/2020 